\title{
Associations of Social Media Use With Physical Activity and Sleep Adequacy Among Adolescents: Cross-Sectional Survey
}

Sandhya V Shimoga ${ }^{*}, \mathrm{PhD}$; Erlyana Erlyana*, MD, PhD; Vida Rebello*, MSHCA

Department of Health Care Administration, California State University Long Beach, Long Beach, CA, United States

*all authors contributed equally

\section{Corresponding Author:}

Erlyana Erlyana, $\mathrm{MD}, \mathrm{PhD}$

Department of Health Care Administration

California State University Long Beach

1250 Bellflower Blvd

Long Beach, CA, 90840

United States

Phone: 15629855800

Fax: 15629855886

Email: erlyana.erlyana@csulb.edu

\section{Abstract}

Background: Adolescents' use of social media, which has increased considerably in the past decade, has both positive and negative influences on adolescents' health and health behaviors. As social media is the most prominent communication tool of choice for adolescents, it is important to understand the relationship between the frequency of social media use and health behaviors among this population.

Objective: The objective of our study was to examine the associations between the frequency of social media use and physical activity and sleep adequacy among middle and high school students.

Methods: We used data from the Monitoring the Future survey (2014 and 2015), a nationally representative, annual, cross-sectional survey of American 8th-, 10th-, and 12th-grade students $(\mathrm{N}=43,994)$. Health behaviors examined were frequency of vigorous physical activity and frequency of getting 7 hours of sleep (never/seldom, sometimes, and every day/nearly every day). We measured frequency of social media use using a Likert-like scale (never, a few times a year, 1-2 times a month, once a week, or every day). Multivariable generalized ordered logistic regressions examined the association of social media use with different levels of physical activity and sleep. We estimated marginal effects (MEs) for the main independent variable (social media use frequency) by holding all other variables at their observed values.

Results: The study population comprised $51.13 \%(21,276 / 42,067)$ female students, $37.48 \%(17,160 / 43,994)$ from the South, and $80.07 \%(34,953 / 43,994)$ from a metropolitan area, with $76.90 \%(33,831 / 43,994)$ reporting using social media every day. Among physically active students, frequent social media use was associated with a higher likelihood of vigorous daily exercise (ME 50.1\%, 95\% CI 49.2\%-51.0\%). Among sedentary students, frequent social media use was associated with a lower likelihood of vigorous daily exercise (ME $15.8 \%, 95 \%$ CI 15.1\%-16.4\%). Moderately active students who used social media once or twice a month had the highest likelihood of reporting vigorous daily exercise (ME 42.0\%, 95\% CI 37.6\%-46.3\%). Among those who normally got adequate sleep, daily social media users were least likely to report adequate sleep (ME 41.3\%, 95\% CI 40.4\%-42.1\%). Among those who were usually sleep deprived, daily social media users were more likely to report adequate sleep (ME $18.3 \%$, 95\% CI $17.6 \%-19.0 \%)$.

Conclusions: Regular social media use every day was associated with a reinforcement of health behaviors at both extremes of health behaviors, whereas a medium intensity of social media use was associated with the highest levels of physical activity and lowest sleep adequacy among those with moderate health behaviors. Hence, finding an optimal level of social media use that is beneficial to a variety of health behaviors would be most beneficial to adolescents who are in the middle of the health behavior spectrum.

(J Med Internet Res 2019;21(6):e14290) doi: $\underline{10.2196 / 14290}$ 


\section{KEYWORDS}

adolescent; social media; exercise; sleep

\section{Introduction}

\section{Background}

Over the past decade, regular use of social media by young adults has increased considerably from $89 \%$ in 2014 to $97 \%$ in 2016 [1]. Villanti and colleagues also reported that young adults used an average of 7.6 social media sites regularly, with $85 \%$ of them using 6 or more sites regularly [1]. Adolescents' time spent on social media has also more than doubled from 4.4 hours weekly in 2007 to 11.1 hours in 2011 [2].

Adolescents are more likely than any other age group to use social media. In 2013, approximately $45 \%$ of adolescents in the United States used social media sites daily and, among those, $73 \%$ used it to connect with their peers $[3,4]$. This extensive use of social media during the formative years calls into question the extent of its influence on all aspects of development, including physical and mental health. An emerging body of evidence shows both positive and negative influences of social media use on adolescents' health and health behaviors [5-8]. The benefits of social media use include exposure to new ideas and information and raising awareness of current events and issues. The interactive nature of social media can provide opportunities to engage with peers on issues, access support networks, and improve social inclusion; it may also foster healthy eating habits [8]. However, there are notable negative health outcomes associated with social media use among adolescents. Higher levels of social media use among this population are associated with lower levels of participation in sports activity, less happiness, and more socioemotional difficulties [9]. Smartphone or mobile phone use at night is associated with reduced and disrupted sleep patterns among adolescents [6,10-12]. High-frequency social media use at night was significantly associated with perceived insufficient sleep [13]. While a high risk of poor-quality sleep or sleep disturbance is associated with frequent social media use among adolescents [11,12,14-16], there is some indication that sleeplessness precedes excessive media use $[17,18]$. Youths who connect with peers face-to-face have positive emotional outcomes compared with those who predominantly use social media to connect with peers $[19,20]$. Mental health conditions including anxiety and depression are exacerbated by excessive social media use among adolescents $[15,21,22]$. The predominant conclusion reached by studies on the relationship between social media use and health behaviors is that the time spent on social media use supplants time spent otherwise on physical activity or sleeping.

While many studies have focused on excessive use of social media or the internet, evidence is emerging that the relationship between intensity of internet use and health outcomes is not necessarily linear. Some recent studies suggested a U-shaped relationship between internet use frequency and depressive symptoms, where both low and high levels of internet use were associated with higher risks for depression and lower levels of mental well-being [21,23]. These studies examined cumulative use of all types of digital platforms. We did not find studies that specifically explored the relationship between frequency of social media use and health behaviors among adolescents.

\section{Objective}

As social media is the most prominent communication tool of choice for adolescents, it is important to understand the relationship between the frequency of social media use and health behaviors among this population. Therefore, in this study, we examined the association between the frequency of social media use and different levels of physical activity and sleep adequacy among middle and high school students in the United States.

\section{Methods}

\section{Data Source}

Data for the study were from the Monitoring the Future (MTF) survey, which is a nationally representative, cross-sectional, annual survey of 8th-, 10th-, and 12th-grade students in the United States. MTF collects data through self-administered questionnaires in approximately 420 high schools and middle schools in the contiguous United States [24,25]. To obtain a nationally representative sample of schools and students, the survey employs a multistage random sampling design with (1) geographic areas or primary sampling units, (2) schools (or linked groups of schools) within primary sampling units, and (3) students within sampled schools. Schools are asked to participate for 2 years, and schools refusing participation are replaced with similar schools in terms of geographic location, size, and type of school. Student response rates for the survey were over $80 \%$ for all grade levels during all the years considered for our study and almost all nonresponse was due to absenteeism.

Data collection procedures were approved by the Institutional Review Board of the University of Michigan and the survey was funded by the National Institute on Drug Abuse. Public-use data files are available from Inter-university Consortium for Political and Social Research. Descriptions of the survey sampling frame, methodology, and response rates are detailed elsewhere [26].

We derived the study sample from MTF surveys conducted in 2014 and 2015. The data consisted of a pooled sample of 43,994 students in the 8th, 10th, and 12th grades who answered the questions on social media use and at least one of the questions on health behaviors. Eighth and 10th graders constituted $44.91 \%$ $(20,011 / 43,994)$ and $45.99 \%(19,549 / 43,994)$ of the study sample, respectively. The questions pertaining to social media use and health behaviors were administered to approximately $20 \%$ of the 12th-grade students during 2014 and 2015 compared with $100 \%$ of the 8 th- and 10th-grade students. Hence, 12th-grade students constituted a smaller portion of the study sample. We limited the selection of data to 2014 and 2015 due to major changes to the questions on social media use in 2014 [24,25]. 


\section{Dependent and Independent Variables}

Our dependent variables were physical activity and sleep adequacy. The MTF survey measured responses to questions on physical activity ("How often do you exercise vigorously?") and sleeping habits ("How often do you get at least seven hours of sleep?") using a Likert-like scale with 5 possible responses: never, seldom, sometimes, most days, nearly every day, and every day. We created our dependent variables by combining adjacent categories of responses. We refer to the 3 levels of outcome variables as never/seldom, sometimes, and every day/nearly every day of physical activity or daily 7 hours of sleep.

We measured the main independent variable, frequency of social media use, by how often the student used social media ("How often do you visit social networking websites like Facebook, Twitter, Instagram, etc.?") using a Likert-like scale with 5 possible responses: never, a few times a year, one to two times a month, once a week, or every day. We included the following individual level covariates in all our models: sex, average letter grade, number of hours of homework per week, grade level, and level of happiness on the day of the survey (very happy, pretty happy, or not too happy). We included school location (in a metropolitan statistical area as defined for the US Census or not) and the Census region in which the school was located to account for regional variations. We included survey year to account for differences between the survey years.

\section{Statistical Analysis}

We used a repeated cross-sectional analysis by pooling survey data from the years 2014 and 2015 for 8th-, 10th-, and 12 th-grade students. We employed multivariable generalized ordered logistic regressions to compare the association of social media use with different levels of physical activity and sleep adequacy. We used generalized ordered logistic models instead of ordered logistic regression models because the ordered logistic models did not meet the proportional odds assumption [27,28]. We tested for the joint significance of different levels of social media use using the adjusted Wald test. We estimated marginal effects (MEs) for the main independent variable, social media use frequency, by holding all other variables at their observed values. All analyses used pooled survey weights derived from the sampling frame sizes provided by
Inter-university Consortium for Political and Social Research, along with the individual sample weights provided in the public-use data files. We conducted all analyses using Stata 14 (StataCorp LLC).

\section{Results}

\section{Sample Characteristics}

The study sample consisted of students who answered questions on social media use and questions on one or both of the health behaviors $(\mathrm{N}=43,994)$. Table 1 presents the characteristics of the study sample over different levels of social media use.

As Table 1 shows, the study population consisted of $51.13 \%$ $(21,276 / 42,067)$ female students; $37.48 \%(17,160 / 43,994)$ were from the South and $80.07 \%(34,953 / 43,994)$ were from a metropolitan statistical area. Approximately half of the study population reported 1-4 hours of homework per week $(21,029 / 42,332,50.08 \%)$ and $75.25 \%(33,392 / 42,133)$ reported letter grades of B- or better. Most $(28,381 / 43,460,65.52 \%)$ of the students reported being pretty happy. Additionally $9.12 \%$ $(4434 / 43,994)$ of the students were 12 th graders, and 8 th and 10th graders accounted equally for the rest of the study population.

Of the 20,879 students who answered both the questions on physical activity and on social media use, almost half $(n=10,033)$ reported being physically active every day or nearly every day, while $17.06 \%(n=3563)$ reported lower levels of physical activity (Table 1). In all levels of social media use, a higher percentage of students reported being physically active regularly and a smaller percentage reported being sedentary.

Of the 20,950 students who answered both the questions on sleep and on social media use, about $41.82 \%(n=8689)$ reported getting 7 hours of sleep nearly every day, while $18.39 \%$ $(n=3986)$ of the students reported never or seldom getting 7 hours of sleep (Table 1). In all levels of social media use except use every day, a higher percentage of students reported getting adequate sleep. Among those who used social media every day, an equal percentage of students reported getting moderately adequate ("sometimes") or adequate levels ("every day/nearly every day") of sleep. 
Table 1. Characteristics of students by frequency of social media use.

\begin{tabular}{|c|c|c|c|c|c|c|c|}
\hline \multirow[t]{2}{*}{ Characteristics } & \multicolumn{6}{|c|}{ Social media frequency observations, n (\%) } & \multirow[t]{2}{*}{$P$ value } \\
\hline & $\begin{array}{l}\text { Never } \\
(n=3087)\end{array}$ & $\begin{array}{l}\text { A few times a } \\
\text { year }(n=990)\end{array}$ & $\begin{array}{l}1-2 \text { times a } \\
\text { month }(n=1607)\end{array}$ & $\begin{array}{l}\text { Once a week } \\
(n=4479)\end{array}$ & $\begin{array}{l}\text { Every day } \\
(n=33,831)\end{array}$ & Total $(\mathrm{N}=43,994)$ & \\
\hline Frequency of physical activity & & & & & & & $<.001$ \\
\hline Never/seldom & $312(22.3)$ & $101(21.0)$ & $145(19.0)$ & $321(16.7)$ & $2684(16.56)$ & $3563(17.14)$ & \\
\hline Sometimes & $499(36.8)$ & $160(37)$ & $304(40.5)$ & $722(36.1)$ & $5598(34.36)$ & $7283(34.98)$ & \\
\hline Every day/nearly every day & $543(40.9)$ & $185(42.0)$ & $307(40.5)$ & $960(47.2)$ & $8038(49.08)$ & $10,033(47.88)$ & \\
\hline \multicolumn{4}{|c|}{ Frequency of sleeping 7 hours/day } & & & & $<.001$ \\
\hline Never/seldom & $206(13.8)$ & $87(20.0)$ & $149(19.2)$ & $352(16.3)$ & $3192(18.96)$ & 3986 (18.39) & \\
\hline Sometimes & $449(33.1)$ & $162(36.0)$ & $270(34.5)$ & 763 (38.7) & $6631(40.83)$ & 8275 (39.79) & \\
\hline Every day/nearly every day & $703(53.1)$ & $196(44.0)$ & $330(46.3)$ & $894(45.0)$ & $6566(40.22)$ & $8689(41.82)$ & \\
\hline Survey year & & & & & & & $<.001$ \\
\hline 2014 & $1553(50.00)$ & $527(53.0)$ & $815(49.7)$ & $2256(50.44)$ & $15,935(47.08)$ & $21,086(47.86)$ & \\
\hline 2015 & $1534(50.00)$ & $463(47.0)$ & $792(50.3)$ & $2223(49.56)$ & $17,896(52.92)$ & $22,908(52.14)$ & \\
\hline Grade & & & & & & & $<.001$ \\
\hline 8th & $1811(58.68)$ & $511(50.0)$ & $754(45.5)$ & $2282(50.79)$ & $14,653(42.68)$ & $20,011(44.91)$ & \\
\hline 10 th & $1105(36.56)$ & $393(42.4)$ & $692(45.3)$ & $1780(40.74)$ & $15,579(47.69)$ & $19,549(45.98)$ & \\
\hline 12 th & $171(4.7)$ & $86(8.0)$ & $161(9.0)$ & $417(8.5)$ & $3599(9.63)$ & $4434(9.11)$ & \\
\hline Sex & & & & & & & $<.001$ \\
\hline Male & $1989(67.46)$ & $670(70.7)$ & $1066(70.13)$ & $2786(63.96)$ & $14,280(43.53)$ & $20,791(48.87)$ & \\
\hline Female & $950(32.5)$ & $272(29.3)$ & 453 (29.9) & $1454(36.04)$ & $18,147(56.47)$ & $21,276(51.13)$ & \\
\hline Region & & & & & & & $<.001$ \\
\hline North east & $572(16.2)$ & $178(17.1)$ & $279(15.0)$ & $829(17.0)$ & $6631(18.18)$ & $8489(17.78)$ & \\
\hline North central & $604(21.3)$ & $204(21.4)$ & $311(22.1)$ & $912(22.1)$ & $6812(22.00)$ & $8843(21.95)$ & \\
\hline South & $1153(35.8)$ & $363(35.1)$ & $630(36.9)$ & $1657(35.32)$ & $13,357(38.02)$ & $17,160(37.48)$ & \\
\hline West & $758(26.7)$ & $245(26.1)$ & $387(26.0)$ & $1081(25.61)$ & $7031(21.80)$ & 9502 (22.79) & \\
\hline Metropolitan statistical area & & & & & & & .01 \\
\hline No & $597(19.5)$ & $222(22.0)$ & 364 (22.9) & $995(21.3)$ & $6863(19.59)$ & $9041(19.93)$ & \\
\hline Yes & $2490(80.5)$ & $768(78.0)$ & $1243(77.11)$ & $3484(78.74)$ & $26,968(80.41)$ & $34,953(80.07)$ & \\
\hline Level of happiness & & & & & & & .03 \\
\hline Not too happy & $502(15.9)$ & $159(17)$ & $285(17.5)$ & $650(14.8)$ & $5448(16.34)$ & 7044 (16.19) & \\
\hline Pretty happy & $1918(63.5)$ & $634(65.7)$ & $1045(66.14)$ & $2945(66.75)$ & $21,839(65.50)$ & $28,381(65.52)$ & \\
\hline Very happy & $623(20.6)$ & $177(17.8)$ & $257(16.4)$ & $815(18.5)$ & $6163(18.16)$ & 8035 (18.29) & \\
\hline Homework (hours/week) & & & & & & & .09 \\
\hline 0 & $210(7.3)$ & $80(9)$ & $142(8.7)$ & 325 (8.09) & $2693(7.98)$ & $3450(7.99)$ & \\
\hline $1-4$ & $1397(47.71)$ & $462(49.8)$ & $773(50.7)$ & $2146(51.08)$ & $16,521(50.14)$ & $21,029(50.08)$ & \\
\hline $5-9$ & $596(20.1)$ & $191(20)$ & $294(19.3)$ & $893(20.6)$ & $6362(19.58)$ & $8336(19.72)$ & \\
\hline $10-14$ & 337 (11.2) & 104 (10.9) & $152(10.1)$ & $422(9.5)$ & 3327 (9.94) & 4342 (9.99) & \\
\hline $15-19$ & $169(5.6)$ & $37(4)$ & $69(5)$ & $235(5.1)$ & $1781(5.47)$ & $2291(5.39)$ & \\
\hline $20-24$ & $123(4.7)$ & $32(4)$ & $43(3)$ & $121(2.8)$ & $1174(3.50)$ & 1493 (3.49) & \\
\hline$\geq 25$ & $99(3)$ & $30(3)$ & $47(3)$ & $125(2.8)$ & $1090(3.40)$ & $1391(3.34)$ & \\
\hline Letter grade & & & & & & & $<.001$ \\
\hline $\mathrm{D}$ & $82(3)$ & $33(4)$ & $58(4)$ & $102(2.5)$ & $856(2.5)$ & $1131(2.63)$ & \\
\hline
\end{tabular}




\begin{tabular}{cllllll}
\hline Characteristics & \multicolumn{2}{l}{ Social media frequency observations, $\mathrm{n}(\%)$} & & & \\
& $\begin{array}{l}\text { Never } \\
(\mathrm{n}=3087)\end{array}$ & $\begin{array}{l}\text { A few times a } \\
\text { year }(\mathrm{n}=990)\end{array}$ & $\begin{array}{l}1-2 \text { times a } \\
\text { month }(\mathrm{n}=1607)\end{array}$ & $\begin{array}{l}\text { Once a week } \\
(\mathrm{n}=4479)\end{array}$ & $\begin{array}{l}\text { Every day } \\
(\mathrm{n}=33,831)\end{array}$ & $\begin{array}{l}\text { Total }(\mathrm{N}=43,994) \\
147(3.7)\end{array}$ \\
\hline $\mathrm{C}-$ & $89(3)$ & $32(4)$ & $68(4)$ & $1194(3.69)$ & $1530(3.68)$ \\
C & $117(4.4)$ & $48(5)$ & $92(6)$ & $278(6.6)$ & $1796(5.55)$ & $2331(5.59)$ \\
C+ & $173(5.6)$ & $81(9)$ & $139(9.3)$ & $403(9.9)$ & $2953(9.09)$ & $3749(8.93)$ \\
B- & $203(6.4)$ & $102(10.4)$ & $160(10.4)$ & $455(10.7)$ & $3308(10.33)$ & $4228(10.11)$ \\
B & $374(13.3)$ & $148(14.4)$ & $236(15.7)$ & $698(16.5)$ & $4968(15.16)$ & $6424(15.16)$ \\
B+ & $461(15.4)$ & $161(17.3)$ & $255(18.5)$ & $676(15.6)$ & $5725(17.71)$ & $7278(17.35)$ \\
A- & $592(20.6)$ & $156(18.4)$ & $231(15.7)$ & $724(17.2)$ & $5707(17.49)$ & $7410(17.62)$ \\
A & $835(28.4)$ & $177(18.8)$ & $256(16.3)$ & $771(17.3)$ & $6013(18.42)$ & $8052(18.93)$ \\
\hline
\end{tabular}

\section{Associations Between Dependent and Independent Variables}

Results of multivariable regressions for physical activity indicated a statistically significant association between frequencies of social media use and physical activity (adjusted Wald test $F_{8,20871}=18.39 ; P<.001$ ); and between frequencies of social media use and sleep adequacy (adjusted Wald test $\left.F_{8,20942}=2.05 ; P=.04\right)$. Table 2 shows the MEs of different impacts of social media use on different levels of physical activity and sleep adequacy. We calculated the MEs holding all other covariates at their observed values.

Among students with a low level of physical activity, the likelihood of reporting physical activity decreased with increasing social media use (for social media nonusers, ME $26.4 \%, 95 \%$ CI $23.4 \%-29.4 \%$, and for daily social media users, ME $15.8 \%, 95 \%$ CI $15.1 \%-16.4 \%$ ). Among students with a higher level of physical activity, the likelihood of reporting physical activity increased with increasing frequency of social media use (for social media nonusers, ME 35.5\%, 95\% CI $32.6 \%-38.5 \%$, and for daily social media users, ME 50.1\%, $95 \%$ CI $49.2 \%-51.0 \%$ ). In contrast to this linear relationship, the relationship among moderately active students peaked with students who used social media once or twice a month reporting the highest likelihood of vigorous exercise (ME 42.0\%, 95\% CI $37.6 \%-46.3 \%)$.

Among students who got inadequate sleep, social media nonusers were less likely to report getting 7 hours of sleep regularly (ME 16.6\%, 95\% CI 14.2\%-18.9\%) than were students who used social media every day (ME 18.3\%, 95\% CI $17.6 \%-19.0 \%$ ). Among those who got adequate sleep, social media nonusers were more likely to report getting 7 hours of sleep (ME 46.6\%, 95\% CI 43.4\%-49.7\%) than were students who were daily social media users (ME 41.3\%, 95\% CI $40.4 \%-42.1 \%$ ). Students who reported moderately adequate sleep and who used social media once or twice a month were least likely report adequate sleep (ME 36.4\%, 95\% CI $32.2 \%-40.6 \%)$

Additional analysis including parental education and race/ethnicity as control variables did not significantly change the reported results. However, including these variables resulted in a smaller sample size, as one-third of the students did not provide parental education data and almost $29.92 \%$ $(13,165 / 43,994)$ of the observations lacked data on race/ethnicity. Hence, we report the original results.

Table 2. Regression results showing the association between health behaviors and frequency of social media use by middle and high school students ${ }^{\mathrm{a}, \mathrm{b}, \mathrm{c}}$.

\begin{tabular}{llllllll}
\hline Social media use frequency & \multicolumn{2}{l}{$\%$ marginal effect $(95 \%$ CI) } & & & & \\
& \multicolumn{2}{l}{ Vigorous physical activity $(\mathrm{n}=19,543)$} & \multicolumn{2}{l}{ Sleeping 7 hours/day $(\mathrm{n}=19,596)$} \\
& Never/seldom & Sometimes & Every day & Never/seldom & Sometimes & Every day \\
\hline Never & $26.4(23.4-29.4)$ & $38.1(34.8-41.3)$ & $35.5(32.6-38.5)$ & $16.6(14.2-18.9)$ & $36.9(33.7-40.0)$ & $46.6(43.4-49.7)$ \\
A few times a year & $24.4(19.8-28.9)$ & $37.8(32.4-43.2)$ & $37.8(32.5-43.1)$ & $21.4(16.9-25.9)$ & $37.9(32.6-43.3)$ & $40.7(35.4-46.0)$ \\
$1-2$ times a month & $20.4(16.9-24.0)$ & $42.0(37.6-46.3)$ & $37.6(33.6-41,6)$ & $19.5(16.2-22.9)$ & $36.4(32.2-40.6)$ & $44.0(39.9-48.2)$ \\
Once a week & $18.6(16.4-20.8)$ & $36.5(33.9-39.1)$ & $44.9(42.3-47.5)$ & $17.4(15.4-19.3)$ & $40.1(37.5-42.8)$ & $42.5(40.0-45.0)$ \\
Every day & $15.8(15.1-16.4)$ & $34.1(33.2-35.0)$ & $50.1(49.2-51.0)$ & $18.3(17.6-19.0)$ & $40.4(39.5-41.4)$ & $41.3(40.4-42.1)$ \\
\hline
\end{tabular}

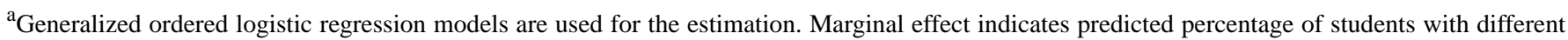
intensities of health behaviors and social media use, holding all the other covariates at their observed values.

${ }^{\mathrm{b}}$ All results are statistically significant at $P<.001$.

${ }^{\mathrm{c}}$ Data are from the Monitoring the Future survey (2014 and 2015) with students from 8th, 10th, and 12th grades. 


\section{Discussion}

\section{Principal Findings}

Our study results indicate that the association between health behaviors and the frequency social media use is significant and the direction of the association differs by whether the health behaviors are at high, medium, or low levels. The health behaviors at both the high and the lower end of the spectrum are reinforced further with more frequent social media use, whereas moderate health behaviors show an interesting nonlinear relationship with the frequency of social media use. We adjusted for reported happiness to account for stress, which may adversely influence health behaviors. While having a higher homework load may take time away from physical activity, sleep, and social media use, we controlled for the homework hours in all models. We also adjusted for grade level, as students in higher grades may have less time for sleep and physical activities due to more academic demands on their time.

The results show that students who were moderately active $(7283 / 20,879,34.98 \%$ of the study sample) or who reported moderately adequate sleep $(8275 / 20,950,39.79 \%$ of the study sample) had a nonlinear relationship with the frequency of social media use. This relationship indicates that a moderate amount of social media use may have a beneficial impact on moderate physical activity and a detrimental influence on moderately adequate sleep among students. Most of the previous research did not delineate different levels of health behaviors, leading to the oversimplified conclusion that more social media use is associated with worse health behaviors. Our results are in line with the emerging literature on the relationship between social media use intensity and other health outcomes, including a U-shaped, nonlinear "Goldilocks effect" of the intensity of internet use on depression and overall mental well-being among adolescents [21,23]. The Goldilocks effect refers to the phenomenon where a moderate intensity of social media use is associated with the highest levels of mental well-being, compared with either too much or too little social media use.

These results are in line with the evidence that users extend their offline personality and behaviors into their online activities [29]. Our results indicate that, among physically active students, frequent social media use was associated with a higher likelihood of daily vigorous physical activity, which may be due to a positive feedback loop from sharing related news or pictures on social media. On the other hand, sedentary behaviors changed for the worse with increased social media use, which may further the supposition that time spent on social media is not available for other activities. Sleeping behaviors of both inadequate and adequate sleepers were reinforced with more frequent social media use. Inadequate sleepers may have had difficulty falling asleep or may have been light sleepers, and such issues were magnified with more social media use. On the other hand, adequate sleepers may have developed sleeping habits that were immune to social media use.

\section{Implications}

These results have several implications for adolescents as their social media use has drastically increased over time. Adolescents' social interactions have increasingly moved to social media platforms. To capitalize on this trend, there has been a marked shift in promoting health behaviors and providing interventions using social media platforms, which contribute to further increases in the frequency of social media use. While there is cause for concern, our study indicates some opportunities. There may be a "sweet spot" where a moderate level of social media use may provide maximum or minimum benefit for a particular health behavior for a specific set of students. The results also suggest that a one-type-fits-all approach may be detrimental to those who are already in the group that is at most risk of adverse behaviors.

While students may engage in vigorous physical activity due to participation in school teams and other organized activities, the levels of physical activity tend to decrease as they graduate from high school, go to college where activities are less structured, and eventually settle into adulthood, when they have to be self-motivated to remain physically active [30]. Unlike physical activity, sleep patterns tend to fluctuate more; however, most of the adult population falls into a moderately adequate sleep category with average reported sleep of less than 6 hours per day [31]. Further, average use of social media does not seem to decrease much as teenagers settle into early adulthood [4,32]. While the relationship between healthy behaviors and social media use in late adulthood may be influenced by additional factors, it is important to understand this nonlinear relationship during early adulthood, when many of the health behaviors are formed. Social media use is shaping up to be a large influencer of health behaviors, with social media-based programs being developed to improve fitness, reduce stress, share experiences on health behaviors, and form support groups to improve health and wellness for all age groups [7,33]. However, there is also growing evidence that social media may promote negative emotions due to excessive social comparison, including those on health behaviors [34-36]. Hence, it is imperative to understand whether there is an optimal level of social media use that has the best impact on health behaviors.

\section{Limitations}

This was a cross-sectional study and, hence, we cannot claim to assess causality between health behaviors and social media use. The study population was a nationally representative sample of students. However, caution should be exercised when generalizing the results to other adolescents who are home schooled or who have dropped out of school.

While there was a survey question on the number of hours spent on social media, a large percentage of the answers were either missing or inconsistent and, hence, not used in this study. Since time used for social media was affecting health behaviors $[6,11,13]$, future studies would benefit from including the actual time spent on social media activities rather than categories.

The data did not include information on specific social media sites visited or on specific activities conducted on social media (such as posting and responding to messages, or creating content). While results indicate reinforcement of both high and low levels of health behaviors, understanding the content and its specific methods of use by students would provide deeper insights into understanding the nonlinear relationship among 
those with moderate health behaviors. Inadequate sleep may be worsened further by social media content.

Students who exercise vigorously may be involved in organized sports activities such as school athletic programs or competitive sports outside the school and, hence, may be more disciplined in their commitment to physical activities. In that case, the effect of social media use on their physical activity levels may be overstated. We controlled for this to some extent by adjusting for academic achievement as a proxy for their intrinsic motivation. Students who sleep less may do so due to issues related to anxiety, depression, or other stressors, which may also influence use of social media. We accounted for this by including level of happiness as a proxy for mental well-being. The survey question on sleep asked about the regularity of getting 7 hours of sleep, whereas the US National Sleep Foundation and American Academy of Sleep Medicine recommend 8 to 10 hours of sleep for teenagers [37]. Hence, the survey possibly underrepresented the inadequacy of sleep. Future studies should include variables that capture sleep quality or problems in addition to questions on sleep duration.

\section{Conclusion}

Our study indicates that regular social media use reinforces health behaviors of adolescents at the extreme ends of the health behavior spectrum. Among adolescents who follow health behaviors to a moderate extent, a moderate use of social media provides the most benefit. Future studies examining the content of social media sites visited and the interaction patterns, as well as the number of hours spent on social media sites, would inform our understanding of the impact of social media use on health behaviors and facilitate using optimal social media to promote health behaviors.

\section{Acknowledgments}

This work was supported by the National Institute of General Medical Sciences of the US National Institutes of Health under award numbers UL1GM118979, TL4GM118980, and RL5GM118978 and by a Summer Research Assistantship from the Office of Research and Sponsored Programs at California State University, Long Beach, Long Beach, CA, USA. The content is solely the responsibility of the authors and does not necessarily represent the official views of the National Institutes of Health.

\section{Conflicts of Interest}

None declared.

\section{References}

1. Villanti AC, Johnson AL, Ilakkuvan V, Jacobs MA, Graham AL, Rath JM. Social media use and access to digital technology in US young adults in 2016. J Med Internet Res 2017 Jun 07;19(6):e196 [FREE Full text] [doi: 10.2196/jmir.7303] [Medline: 28592394]

2. Children and parents: media use and attitudes report. London, UK: Ofcom; 2017 Nov 29. URL: https://www.ofcom.org.uk/ data/assets/pdf file/0020/108182/children-parents-media-use-attitudes-2017.pdf [accessed 2019-06-06] [WebCite Cache ID 78w0ojT8S]

3. Duggan M, Ellison NB, Lampe C, Lenhart A, Madden M. Social media update 2014. Washington, DC: Pew Research Center; 2015 Jan 09. URL: https://www.pewresearch.org/wp-content/uploads/sites/9/2015/01/PI SocialMediaUpdate20144. pdf [accessed 2019-06-06] [WebCite Cache ID 78w14Jy9d]

4. Lenhart A, Purcell K, Smith A, Zickuhr K. Social media \& mobile internet use among teens and young adults. Washington, DC: Pew Internet \& American Life Project; 2010 Feb 03. URL: https://www.pewinternet.org/2010/02/03/ social-media-and-young-adults/ [accessed 2019-06-06]

5. Jelenchick LA, Eickhoff J, Christakis DA, Brown RL, Zhang C, Benson M, et al. The Problematic and Risky Internet Use Screening Scale (PRIUSS) for Adolescents and Young Adults: scale development and refinement. Comput Human Behav 2014 Jun 01;35:171-178 [FREE Full text] [doi: 10.1016/j.chb.2014.01.035] [Medline: 24882938]

6. Bruni O, Sette S, Fontanesi L, Baiocco R, Laghi F, Baumgartner E. Technology use and sleep quality in preadolescence and adolescence. J Clin Sleep Med 2015 Dec 15;11(12):1433-1441 [FREE Full text] [doi: 10.5664/jcsm.5282] [Medline: 26235161]

7. Vaterlaus JM, Patten EV, Roche C, Young JA. \#Gettinghealthy: the perceived influence of social media on young adult health behaviors. Comput Hum Behav 2015 Apr;45:151-157. [doi: 10.1016/j.chb.2014.12.013]

8. Council on Communications and Media. Media use in school-aged children and adolescents. Pediatrics 2016 Nov;138(5):e20162592. [doi: 10.1542/peds.2016-2592] [Medline: 27940794]

9. Booker CL, Skew AJ, Kelly YJ, Sacker A. Media use, sports participation, and well-being in adolescence: cross-sectional findings from the UK household longitudinal study. Am J Public Health 2015 Jan;105(1):173-179. [doi: 10.2105/AJPH.2013.301783] [Medline: 25494209]

10. Börnhorst C, Wijnhoven TMA, Kunešová M, Yngve A, Rito AI, Lissner L, et al. WHO European Childhood Obesity Surveillance Initiative: associations between sleep duration, screen time and food consumption frequencies. BMC Public Health 2015 Apr 30;15:442 [FREE Full text] [doi: 10.1186/s12889-015-1793-3] [Medline: 25924872]

11. Arora T, Broglia E, Thomas GN, Taheri S. Associations between specific technologies and adolescent sleep quantity, sleep quality, and parasomnias. Sleep Med 2014 Feb;15(2):240-247. [doi: 10.1016/j.sleep.2013.08.799] [Medline: 24394730] 
12. Fobian AD, Avis K, Schwebel DC. Impact of media use on adolescent sleep efficiency. J Dev Behav Pediatr 2016 Jan;37(1):9-14 [FREE Full text] [doi: 10.1097/DBP.0000000000000239] [Medline: 26651090]

13. Reynolds AC, Meltzer LJ, Dorrian J, Centofanti SA, Biggs SN. Impact of high-frequency email and instant messaging (E/IM) interactions during the hour before bed on self-reported sleep duration and sufficiency in female Australian children and adolescents. Sleep Health 2019 Dec;5(1):64-67. [doi: 10.1016/j.sleh.2018.10.008] [Medline: $\underline{30670168]}$

14. Levenson JC, Shensa A, Sidani JE, Colditz JB, Primack BA. The association between social media use and sleep disturbance among young adults. Prev Med 2016 Apr;85:36-41 [FREE Full text] [doi: 10.1016/j.ypmed.2016.01.001] [Medline: 26791323]

15. Woods HC, Scott H. \#Sleepyteens: social media use in adolescence is associated with poor sleep quality, anxiety, depression and low self-esteem. J Adolesc 2016 Dec;51:41-49. [doi: 10.1016/j.adolescence.2016.05.008] [Medline: 27294324]

16. Xanidis N, Brignell CM. The association between the use of social network sites, sleep quality and cognitive function during the day. Comput Hum Behav 2016 Feb;55:121-126. [doi: 10.1016/j.chb.2015.09.004]

17. Dijk DJ. Not so fast: sleep and media use. J Sleep Res 2014 Aug;23(4):363 [FREE Full text] [doi: 10.1111/jsr.12212] [Medline: 25073803 ]

18. Tavernier R, Willoughby T. Sleep problems: predictor or outcome of media use among emerging adults at university? J Sleep Res 2014 Aug;23(4):389-396. [doi: 10.1111/jsr.12132] [Medline: 24552437]

19. Meena PS, Mittal PK, Solanki RK. Problematic use of social networking sites among urban school going teenagers. Ind Psychiatry J 2012 Jul;21(2):94-97. [doi: 10.4103/0972-6748.119589] [Medline: 24250039]

20. Moreno MA, Jelenchick L, Cox E, Young H, Christakis DA. Problematic internet use among US youth: a systematic review. Arch Pediatr Adolesc Med 2011 Sep;165(9):797-805 [FREE Full text] [doi: 10.1001/archpediatrics.2011.58] [Medline: 21536950]

21. Bélanger RE, Akre C, Berchtold A, Michaud P. A U-shaped association between intensity of internet use and adolescent health. Pediatrics 2011 Feb;127(2):e330-e335. [doi: 10.1542/peds.2010-1235] [Medline: 21242218]

22. Li W, O'Brien JE, Snyder SM, Howard MO. Characteristics of internet addiction/pathological internet use in U.S. university students: a qualitative-method investigation. PLoS One 2015;10(2):e0117372 [FREE Full text] [doi: 10.1371/journal.pone.0117372] [Medline: 25647224]

23. Przybylski AK, Weinstein N. A large-scale test of the Goldilocks hypothesis. Psychol Sci 2017 Dec;28(2):204-215. [doi: 10.1177/0956797616678438] [Medline: 28085574]

24. Johnston LD, Bachman JG, O'Malley PM, Schulenberg JE, Miech RA. Monitoring the Future: A Continuing Study of American Youth (8th- and 10th-Grade Surveys). Ann Arbor, MI: Inter-university Consortium for Political and Social Research; 2016.

25. Johnston LD, Bachman JG, O'Malley PM, Schulenberg JE, Miech RA. Monitoring the Future: A Continuing Study of American Youth (12th-Grade Survey). Ann Arbor, MI: Inter-university Consortium for Political and Social Research; 2017.

26. Bachman JG, Johnston LD, O'Malley PM, Schulenberg JE, Miech RA. The Monitoring the Future Project after Four Decades: Design and Procedures. Monitoring the Future Occasional Paper Series. Paper 82. Ann Arbor, MI: Institute for Social Research, University of Michigan; 2015.

27. Long SJ, Long JS, Freese J. Regression Models for Categorical Dependent variables Using Stata. College Station, TX: Stata Press; 2006.

28. Williams R. Understanding and interpreting generalized ordered logit models. J Math Sociol 2016 Jan 29;40(1):7-20. [doi: 10.1080/0022250X.2015.1112384]

29. Gosling SD, Augustine AA, Vazire S, Holtzman N, Gaddis S. Manifestations of personality in online social networks: self-reported Facebook-related behaviors and observable profile information. Cyberpsychol Behav Soc Netw 2011 Sep;14(9):483-488 [FREE Full text] [doi: 10.1089/cyber.2010.0087] [Medline: 21254929]

30. Gordon-Larsen P, Nelson MC, Popkin BM. Longitudinal physical activity and sedentary behavior trends: adolescence to adulthood. Am J Prev Med 2004 Nov;27(4):277-283. [doi: 10.1016/j.amepre.2004.07.006] [Medline: 15488356]

31. Ford ES, Cunningham TJ, Croft JB. Trends in self-reported sleep duration among US adults from 1985 to 2012 . Sleep 2015 May 01;38(5):829-832 [FREE Full text] [doi: 10.5665/sleep.4684] [Medline: 25669182]

32. Perrin A. Social networking usage: 2005-2015. Washington, DC: Pew Research Center; 2015 Oct 08. URL: https://www. pewresearch.org/wp-content/uploads/sites/9/2015/10/PI_2015-10-08_Social-Networking-Usage-2005-2015_FINAL.pdf [accessed 2019-06-06] [WebCite Cache ID 78w1Yz4qH]

33. Looyestyn J, Kernot J, Boshoff K, Maher C. A web-based, social networking beginners' running intervention for adults aged 18 to 50 years delivered via a Facebook group: randomized controlled trial. J Med Internet Res 2018 Feb 26;20(2):e67 [FREE Full text] [doi: 10.2196/jmir.7862] [Medline: 29483065]

34. Tiggemann M, Slater A. NetGirls: the internet, Facebook, and body image concern in adolescent girls. Int J Eat Disord 2013 Sep;46(6):630-633. [doi: 10.1002/eat.22141] [Medline: 23712456]

35. Lee SY. How do people compare themselves with others on social network sites? The case of Facebook. Comput Hum Behav 2014 Mar;32:253-260. [doi: 10.1016/j.chb.2013.12.009]

36. Haferkamp N, Krämer NC. Social comparison 2.0: examining the effects of online profiles on social-networking sites. Cyberpsychol Behav Soc Netw 2011 May;14(5):309-314. [doi: 10.1089/cyber.2010.0120] [Medline: 21117976] 
37. Hirshkowitz M, Whiton K, Albert SM, Alessi C, Bruni O, DonCarlos L, et al. National Sleep Foundation's updated sleep duration recommendations: final report. Sleep Health 2015 Dec;1(4):233-243. [doi: 10.1016/j.sleh.2015.10.004] [Medline: $\underline{29073398]}$

\section{Abbreviations}

MTF: Monitoring the Future

ME: marginal effect

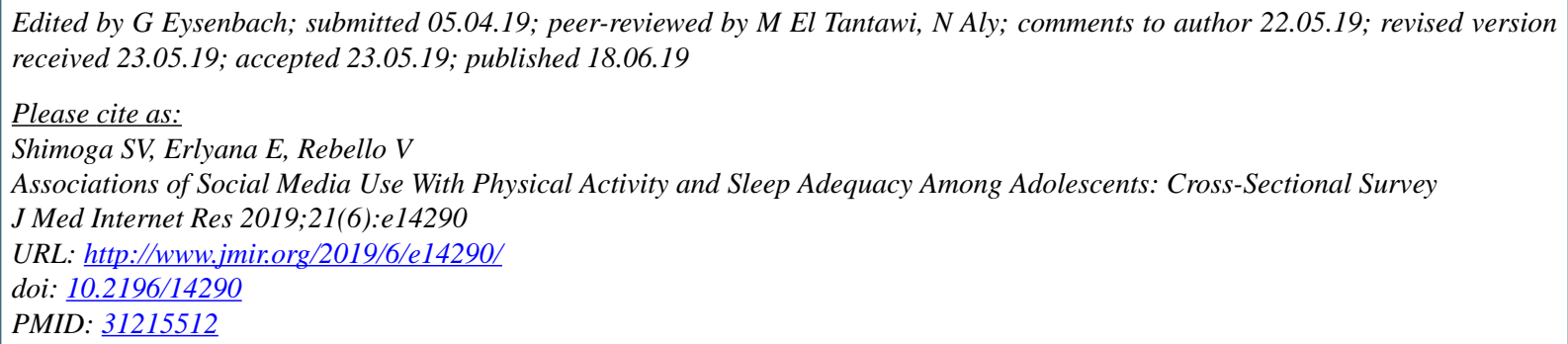

(C) Sandhya V Shimoga, Erlyana Erlyana, Vida Rebello. Originally published in the Journal of Medical Internet Research (http://www.jmir.org), 18.06.2019. This is an open-access article distributed under the terms of the Creative Commons Attribution License (https://creativecommons.org/licenses/by/4.0/), which permits unrestricted use, distribution, and reproduction in any medium, provided the original work, first published in the Journal of Medical Internet Research, is properly cited. The complete bibliographic information, a link to the original publication on http://www.jmir.org/, as well as this copyright and license information must be included. 